\title{
HUME E O ARGUMENTO DO DESÍGNIO*
}

\author{
Marcos Rodrigues da Silva** \\ mrs.marcos@uel.br
}

RESUMO Neste artigo pretendo apresentar a crítica de Hume ao argumento do desígnio bem como algumas interpretações acerca desta crítica, a partir de João Paulo Monteiro, Graham Oppy, Daniel Dennett e Richard Dawkins.

Palavras-Chave Hume, Argumento do Desígnio, Explicação Científica

ABSTRACT In this paper I intend to show Hume's critique concerning the design argument and a few readings - such as João Paulo Monteiro, Graham Oppy, Daniel Dennett and Richard Dawkins - about this critique additionally.

Keywords Hume, Design Argument, Scientific Explanation

* Este texto é parte da tese de doutorado do autor, Breve Jornada Empirismo Adentro, defendida em fevereiro de 2003 na Universidade de São Paulo (USP), sob orientação de Caetano Ernesto Plastino. Uma primeira versão foi apresentada em setembro de 2000, durante os seminários do professor João Paulo Monteiro, a quem agradeço as sugestões.

** Professor da Universidade Estadual de Londrina (UEL). Artigo recebido em dez./04 e aprovado em jul./05. 
A seção XI da Investigação sobre o Entendimento Humano inicia com uma rápida exposição de Hume acerca do problema da influência das idéias filosóficas nos costumes e na vida social. Em suma, os filósofos, no albor da filosofia, teriam desfrutado do maravilhoso privilégio da liberdade intelectual (com exceção de Protágoras e Sócrates); em seguida, no entanto, Hume adverte sub-repticiamente o leitor para a necessidade desta atitude de tolerância intelectual que se encontraria ausente (ao menos em parte) em seu tempo. Após o discurso inicial entra em cena um personagem, que admite inicialmente, com Hume, que efetivamente a filosofia não seria portadora de restrições sociais. No entanto, argumenta que o problema levantado por Hume, a saber, o da mudança de atitude com relação à filosofia, seria facilmente caracterizado: o núcleo da forma argumentativa filosófica, longe de ser rejeitado, teria sido incorporado por filósofos que, ao invés de perfilaram-se às mesmas conclusões céticas que amiúde deveriam ser inferidas da reflexão filosófica estariam a avançar na direção oposta; ou seja, argumentos filosóficos, via de regra destinados a cumprir a função de severos e rigorosos censores das crenças e superstições, estariam agora a serviço destas mesmas crenças nefandas. A resposta de Hume ao aborrecimento de seu interlocutor é marcada por um cortante pragmatismo. Naturalmente, afirma Hume, é legítima a adoção de tais estratégias argumentativas da parte dos adversários dos céticos, uma vez que o não estabelecimento de certas crenças (como a crença na existência divina), poderiam dar margem à corrupção de certos valores sociais resultando então que a própria vida comunitária estaria ameaçada - pois, por qual razão outra, que não o temor do castigo eterno divino, alguém se sujeitaria a regular seu padrão de conduta tabulando-o com os hieráticos princípios da religião? $\mathrm{O}$ personagem, após ouvir esta pequena réplica de Hume, e objetar rapidamente que na verdade não há razões filosóficas em jogo por parte dos adversários dos filósofos, mas sim preconceitos e paixões, transmuta-se então num orador epicuriano e procura mostrar a Hume a eficiência de seu argumento.

Preliminarmente, admite ele que o problema da providência é o mais profundo dos problemas filosóficos, lembrando sempre que as conseqüências da especulação a seu respeito não devem ser tomadas como oferecendo qualquer ameaça à ordem social. $\mathrm{O}$ epicurista rejeita a diligência dos pensadores que procuraram levar às últimas conseqüências a investigação filosófica que os conduziu a demonstrar a força do argumento a favor da existência de um planejador do universo. Em seguida, acrescenta que esse seu argumento não poderia ser utilizado como uma instância negativa com respeito ao funcionamento e ordenamento da vida social. E, após admitir que não estaria a negar a existência divina, o epicurista enfatiza que o principal ou único argumento em 
favor dela seria o da ordem natural. Há ordem demais, e isto não poderia ser por acaso: a observação do curso regular da natureza nos conduz à conclusão de que a disposição natural percebida é produto de um planejador. Todavia, o argumento seria construído partindo-se dos efeitos para a causa; quer dizer, da ordem natural inferimos o planejador. Mas deve existir proporcionalidade na relação causal: não se pode atribuir à causa nada além do que se pode perceber no efeito. E é exatamente neste ponto que a seção começa a se tornar interessante, em virtude do problema que se origina da questão da proporcionalidade da relação causal.

Pressuponha-se, como faz o epicurista, que efetivamente a criação seja o produto de um criador (ou criadores). Naturalmente (se aceitamos este pressuposto), não negamos que a ordenação do universo esteja em relação proporcional à causa. Nesse sentido, a harmonia, o ajuste, o equilíbrio seriam resultados de um criador extremamente inteligente. Ou seja, não se está a negar, até aqui, que o universo seja realmente um processo articulado por um criador.

Bem, se não se nega isto, o que se nega então? Parece tentador utilizar, neste contexto, a chamada teoria semântica de Hume. Assim, poderíamos alegar que a idéia que possuímos de um criador é uma entidade desprovida de qualquer significado, uma vez que ela não poderia ser, neste caso, cópia de uma impressão. Contudo, não é esta a linha argumentativa sugerida pelo epicurista. Ou por outra, não é exatamente o problema de uma "teoria do significado" que está a incomodar o epicurista. ${ }^{1}$ Antes, o epicurista está a pensar na construção de um argumento que guarda semelhança com o problema da indução. Senão vejamos. Vamos admitir novamente a pressuposição antes feita: a ordenação do universo sugere como sua causa um criador. Seria legítimo inferir como causa do universo um criador. No entanto, não seria legítimo inferirmos que sua ação seria permanente. Ou seja, da mesma forma que não podemos assegurar que o sol nascerá amanhã, ainda que ele o tenha feito todos os dias até agora, não podemos igualmente ter a certeza de que a ação do criador continuará a ser exercida. A razão para isto é bastante simples: do efeito atual podemos inferir uma causa, mas disto não se segue necessariamente que no futuro a mesma causa continuará a exercer seu poder. Então, é possível que a causa cesse de produzir os efeitos familiares. Em suma, o epicurista parece achar plausível que se admita um criador como causa; mas, uma vez que este argumento tem seu débito de validade com os efeitos, não se pode inferir que a causa tenha qualquer outro atributo que não seja permitido pela observação dos efeitos (a proporcionalidade antes admitida). O atributo da perfeição do 
criador pode até ser admitido, mas ele não pode exceder aquilo que efetivamente observamos até o presente. ${ }^{1}$

Adicionalmente, o epicurista argumenta que a hipótese da ação permanente do planejador decorre também do fato de que os seres humanos possuem a tendência de acreditar numa semelhança de seus desígnios com o do criador. A crença na regularidade natural nos conduz, afirma o epicurista, a crer igualmente que o planejador optará pela continuidade da regularidade. Mais uma vez, o epicurista rejeita esta hipótese pela fraqueza analógica que ela exibe: não se segue do comportamento habitual dos seres humanos (e de suas crenças) o comportamento do planejador. Além disso, os efeitos do comportamento humano poderiam ser rastreados até suas causas (observáveis), mas os efeitos da ação do planejador continuariam para sempre inacessíveis. Note-se bem que o epicurista nega apenas a analogia, não o fato de que se poderia inferir o planejamento, mesmo que a causa deste fosse (como seria neste caso) inobservável.

Apenas concluo esta reconstrução da seção XI da Investigação sobre o Entendimento Humano, lembrando que a intervenção final de Hume na seção aponta para sua sugestão de que o argumento combatido pelo epicurista, pelo fato de se estruturar na passagem dos efeitos para a causa, realmente teria alguma dificuldade em ser estabelecido. Mas é interessante perceber que, ao contrário do que ocorre nos Diálogos, Hume adota aqui uma atitude bastante cautelosa, pois ele não referenda o discurso do epicurista, mas limita-se a considerar que seus argumentos estabelecem certas dificuldades para a idéia de planejador.

Até aqui, o argumento do epicurista apenas levantou a hipótese de que a concepção de um planejador do universo não deve ser preferida a outra qualquer, na medida em que a pressuposição da ação contínua do criador não pode ser sustentada. Contudo, a perplexidade de Hume com relação ao argumento do planejador não esteve adstrita ao discurso do epicurista. O problema reaparece nos Diálogos e com uma estrutura ligeiramente modificada, uma vez que, ali, discute-se à exaustão o célebre argumento do desígnio e, diferentemente do que ocorrera na Investigação sobre o Entendimento Humano, Hume se empenhará em construir uma alternativa a este argumento. ${ }^{2}$ A obra é o relato de um jovem chamado Panfilo a um amigo seu, Hérmipo, que não comparece aos diálogos. Panfilo é discípulo de Cleantes, que nos Diálogos defenderá o argumento a

2 Ou seja, um defensor do argumento do desígnio não poderá sustentar que o argumento prossegue a partir do ponto em que Hume interrompe seu argumento alternativo. 
posteriori nas questões relativas à natureza de Deus. ${ }^{1} \mathrm{O}$ debate conta ainda com mais dois contendores: Demea, que sustenta, ao contrário de Cleantes, a utilização de argumentos a priori para o problema da divindade, e Filo, que representa, ao que tudo indica, a posição do próprio Hume. É interessante perceber que, ainda que rejeite como prova tanto o argumento a priori quanto o argumento a posteriori, nos Diálogos Hume estabelece, creio, um debate apenas com o argumento a posteriori. Além disso, Filo e Demea concordam com a idéia (em oposição a Cleantes), de que a experiência não pode se constituir como uma fonte de conhecimento da natureza de Deus. E é exatamente este o núcleo do argumento de Cleantes; para este, a experiência revela uma harmonia e ordem insuspeitas. A conclusão é simples: há um planejamento, um desígnio que tornou as coisas o que elas são.

Como já vimos, o discurso do epicurista na seção XI da Investigação sobre o Entendimento Humano já pressupunha o argumento do desígnio; contudo, sua objeção ao argumento era extraída da impossibilidade de se demonstrar que este planejamento inicial continuaria a se exercer pelo futuro. Nos Diálogos, Hume (por intermédio de Filo) ataca o argumento do desígnio através de outras estratégias. Em primeiro lugar, ele mantém um acordo com Demea, no sentido de que a natureza de Deus (pressupondo-a com seus atributos familiares, como onipotência, onisciência e bondade infinitas), por ser inatingível a seres providos de recursos cognitivos tão limitados como os nossos, não poderia ser conhecida através da experiência. Em segundo lugar, a experiência seria uma prova de um princípio ordenador, não da natureza ou de Deus, mas de nossa própria mente. Em terceiro lugar, a experiência revela não apenas a bondade infinita de Deus, mas também traria consigo a maldade; neste caso, ou Deus seria também responsável pela maldade, ou então seria incapaz de detê-la - de qualquer modo, em um ou outro caso, faltaria a ele um ou outro atributo. Enfim, os Diálogos fornecem novos argumentos contra a idéia do planejador e no decorrer da discussão destes argumentos surge uma questão inteiramente distinta da discutida na seção XI da Investigação sobre o Entendimento Humano. Mas o mais importante, penso, é que a seção XI da Investigação sobre o Entendimento Humano pressupunha, para fins de argumento, que seria possível a inferência da existência de um planejador partindo-se dos efeitos para a causa. Pode-se dizer que não ocorrera ali a perplexidade de Hume com relação ao problema ainda mais profundo que surge com a pressuposição que foi feita pelo epicurista. E se a seção XI da Investigação 
sobre o Entendimento Humano apenas opunha uma objeção à justificação da idéia da ação permanente da providência divina, nos Diálogos, ao contrário, a discussão avança com a postulação de uma outra hipótese para o problema do ordenamento natural. Nesse sentido, se os argumentos do epicurista devem ser entendidos como negativos, os Diálogos podem ser compreendidos como um momento construtivo da filosofia de Hume no que diz respeito ao problema do ordenamento natural. Acrescente-se a isto que a seção XI da Investigação sobre o Entendimento Humano segue a orientação filosófica do restante da obra; ao passo que os Diálogos inserem o problema numa outra perspectiva, que, como já afirmei, considero, antes de cética ${ }^{1}$ e construtiva.

Lembremos que na seção XI da Investigação sobre o Entendimento Humano o argumento do epicurista limitava-se a denunciar que, ainda que pressuposto um planejador, não se poderia inferir daí a permanência de sua ação. É claro que o epicurista estaria a sugerir um prenúncio do argumento do desígnio, mas ele não o desenvolveu. Tratou do problema da continuidade da ação do planejador; tratou de responder a objeção da analogia entre os efeitos humanos e efeitos divinos; e tratou de assegurar que sua hipótese seria inofensiva ao senso comum. Mas ele não tratou do argumento do desígnio. Quero deixar claro que não estou apontando isto com o objetivo de demonstrar discrepâncias entre os dois textos; pelo contrário, quero sugerir que, na verdade, Hume adotou duas estratégias argumentativas distintas (embora obviamente relacionadas) para atacar o problema. Não obstante, esta afirmação precisa ser qualificada e, ao fazê-lo, tenho por alvo o que julgo ser o objetivo central de Hume nos Diálogos.

Qual seria este objetivo central? Estaria Hume interessado em desqualificar a teologia de seu tempo, ou mesmo a teologia natural, buscando demonstrar que a natureza de Deus não pode ser conhecida? ${ }^{2}$ Ora, fosse este o objetivo de Hume, por que então não reeditar o argumento da seção XI da Investigação sobre o Entendimento Humano a fim de fornecer ainda mais plausibilidade ao seu discurso "anti-teológico"? Se a questão fosse simplesmente liquidar a possibilidade do conhecimento da natureza de Deus, o argumento da seção XI ou seria suficiente ou seria um movimento adicional em direção à refutação do argumento do desígnio. ${ }^{3}$ Afinal de contas, como poderia Cleantes resistir ao discurso do epicurista? Por tudo isso, a "limitação" da seção XI da Investigação sobre o Entendimento Humano já é uma pista interessante para compreendermos

Com isto não quero sugerir, como talvez se possa pensar, que considero a Investigação sobre o Entendimento Humano um tratado cético. Infelizmente, o tema foge aos propósitos deste artigo.

2 MOUNCE, 1999, p. 99.

3 Claro, sabemos que um argumento é tanto mais robusto (mas não necessariamente mais completo) quanto mais aponta instâncias problemáticas para a tese que deseja refutar; mas neste caso Hume estaria apenas a acumular razões em favor da rejeição à teologia natural. 
a necessidade dos Diálogos. Além disso, como lembra Mounce, demarcar meridianamente a teologia de nosso sistema ordinário de crenças pelo fato de que a primeira é sustentada pela fé e o último seria "provado" racionalmente, pareceria algo bastante dissonante com a própria filosofia de Hume, na medida em que mesmo nossas crenças sobre as regularidades não podem ser provadas; argumenta que "a razão é impotente sem uma crença para sustentá-la". ${ }^{1}$ $\mathrm{Na}$ verdade, creio que há uma outra hipótese, e esta possui a vantagem de que se possa, inclusive, situar os Diálogos numa perspectiva mais ampla. Esta hipótese postula que o argumento de Hume nos Diálogos deve ser compreendido como 1) um argumento que se destina a problematizar a necessidade do planejador que resultaria de nosso espanto com a harmonia natural e como 2) um argumento que tenta explicar, sem a pressuposição do desígnio, o fato da ordenação natural. ${ }^{2}$ Não restam dúvidas quanto à existência de uma concordância entre Hume e Cleantes no sentido de que, para ambos, o único argumento a favor da existência do planejador que seria "digno de consideração" seria o argumento do desígnio. Mounce (entre outros, como Ayer) também admite esta hipótese, afirmando que Hume "reconhece a força do argumento do desígnio" (1999, p. 115). Penso que isto deva ser ressaltado, na medida em que, se Ayer e Mounce estiverem certos, a hipótese de que Hume redigiu os Diálogos com uma verve anti-teológica seria tremendamente enfraquecida ou, no mínimo, deveria ser considerada bastante desinteressante. ${ }^{3}$ Deste modo,

1 MOUNCE, 1999, p. 107.

2 Diálogos, VI, IX.

3 Mounce avança igualmente uma hipótese interessante. Hume, ao rejeitar o argumento do desígnio, o faria por razões de paridade com sua própria epistemologia. A experiência é uma instância epistemológica insuficiente para fornecer uma explicação, seja das "conclusões na ciência" seja das conclusões na "teologia natural" (MOUNCE, 1999, p. 110). No entanto, Mounce trata indistintamente os argumentos da seção XI da Investigação sobre o Entendimento Humano e os argumentos dos Diálogos. Para ele, quando Hume nega o princípio da ação permanente da providência, ele estaria igualmente a negar a legitimidade da ciência; como não se pode inferir do efeito mais do que aquilo que é percebido no próprio efeito (a causa deve ser proporcional ao efeito), então, como argumenta Mounce (1999, p.111), não se poderia inferir da harmonia do mundo a existência da providência, pois seria atribuir ao efeito propriedades que nele estão ausentes. Ora, Hume tinha perfeita noção desta dificuldade e a tratou como convinha através de duas estratégias distintas. Em primeiro lugar, na seção XI da Investigação sobre o Entendimento Humano, pressupôs a ação da providência e limitou-se a apontar algumas dificuldades para esta hipótese. Já nos Diálogos, Hume enfrentou a árdua tarefa de justapor uma alternativa que, ao que eu saiba, jamais considerou verdadeira, mas apenas (como torna-se claro na parte VIII dos Diálogos) mais plausível. Da mesma forma, Hume nunca considerou verdadeira sua hipótese do hábito, mas apenas a hipótese mais plausível. Registre-se que eu considero de extrema importância ressaltar esta leitura de Mounce, pois ela auxilia-nos a compreender a importância de separar metodologicamente as estratégias utilizadas por Hume nos dois textos que estão em questão. Se tomamos simplesmente o método empirista de Hume como um guia para rejeitar as hipóteses teológicas, temos de tomá-lo também como uma boa razão para suspeitar de qualquer hipótese acerca da harmonia natural (e, como bem argumenta Mounce, de qualquer hipótese científica). No entanto, desde a formulação da hipótese do hábito (pelo menos), Hume se assume como um filósofo construtivo, e esta atitude não é abandonada nos Diálogos. Esta atitude, talvez por razões de estratégia metodológica, foi abandonada na seção XI da Investigação sobre o Entendimento Humano, onde nenhuma hipótese alternativa foi proposta. Contudo, como a parte VIII dos Diálogos mostra, Hume adianta uma interessante hipótese rival ao argumento do desígnio. 
parece tentador inferir daí que Hume, efetivamente, estava a tratar antes do problema da harmonia natural (para o qual sua solução apontará um caminho para uma interpretação empirista da inferência da melhor explicação) do que propriamente de questões teológicas pois, do contrário, sua preocupação com o argumento a priori ocuparia outra grande parte dos Diálogos. Naturalmente, era típico de sua época que a solução ao problema da harmonia natural fosse procurada no âmbito de um quadro conceitual alicerçado em bases religiosas, o que obrigava Hume a se mover neste mesmo quadro conceitual e cultural disponível e, por isso, discutir argumentos como o argumento do desígnio.

O contra-argumento ao argumento do desígnio, fornecido por Hume, pode ser encontrado na parte VIII dos Diálogos. No início desta seção, Filo retoma (de forma ligeiramente modificada) o argumento de Hume acerca da impossibilidade de demonstração de uma questão de fato. Os tópicos da razão humana são resolvidos com base numa única conclusão; assim procedem as ciências demonstrativas. Mas uma questão de fato (como o problema em pauta no livro) admite diversas perspectivas que são, além disso, indecidíveis num embate teórico em termos de sua verdade. Estabelecido isto, deveria o empirista abrir mão de poder classificar (não em termos de verdade, mas de, digamos, razoabilidade) estas hipóteses rivais? Filo oferece um argumento contrário a esta temível perspectiva.

Em virtude de uma proposta de Filo acerca do sistema de Epicuro como uma hipótese cosmogônica, Demea, bastante assustado, replica que, com a proposta de Filo-Epicuro, a matéria poderia agir sem a intervenção da mente (ou de um agente causal espiritual, ou de Deus). Para Filo, é exatamente esta hipótese (a da ação material sendo explicada pela própria ação material) que deve ser tomada a sério. Isto não significa, contudo, que uma outra hipótese, como a de que a produção do movimento é causada pela mente (ou Deus), deva ser desconsiderada. Ao invés, as duas devem ser tomadas como hipóteses rivais e, mais importante, as duas devem ser consideradas legítimas. Ora, os Diálogos oferecem uma bateria de contra-argumentos a respeito do desígnio; mas oferecem, o que é mais importante, algumas pistas interessantes de uma hipótese que seria construída cento e poucos anos depois: a hipótese darwinista. Neste sentido, concordo integralmente com Oppy, para quem Hume (ainda que num sentido apenas teórico) tenha oferecido, sim, uma antecipação de uma idéia central em Darwin; ou seja, Hume não estava simplesmente demonstrando que o argumento do desígnio era um argumento estruturalmente desqualificado ou mesmo paroquial: de fato, Hume estava a propor 
uma alternativa. ${ }^{1}$ Esta seria a seguinte: suponhamos que a ação na matéria não seja causada por um agente espiritual, mas pela própria matéria. Como esta ação não foi planejada pode-se dizer que, num "primeiro momento", tal ação é bastante desorganizada. Contudo, o caos inicial pretérito seria seguido por um movimento que impusesse ordem à matéria. De acordo com a hipótese de Filo, isto é um fato. Ora, o que é, neste caso, um fato? A ordem natural. Assim, pareceria desapontador que, diante deste fato, pudesse redargüir o defensor do argumento do desígnio: sim, e é a esta ordem que apelo a fim de sustentar meu argumento de que, a não ser que se postule um designer, a ordem permanecerá inexplicada. No entanto, a performance de Filo nem sempre é reconhecida pelos comentadores como um momento construtivo da filosofia de Hume. Vejamos então alguns comentários que não aceitam a inserção de Hume no quadro explicativista que estou a delinear.

De acordo com Dennett, em A Perigosa Idéia de Darwin, Hume, ao rejeitar o argumento do desígnio, estaria a liquidar a noção metafísica de que somente um ser inteligente poderia ser responsável pelo planejamento da natureza. O itinerário de Dennett começa em John Locke, ${ }^{2}$ para quem a matéria, espontaneamente, nada pode produzir - não pode produzir seu próprio movimento. É necessário um princípio que coloque a matéria em movimento, e este princípio seria a Mente. Assim, é a Mente que causa o surgimento da matéria e seu movimento. Esta Mente é uma propriedade de um ser inteligente com capacidade para o planejamento. Para Dennett, o argumento de Hume nos Diálogos seria uma réplica a Locke; no entanto, o argumento não passaria disso. Na perspectiva de Dennett, Hume estaria a adiantar algumas idéias de Darwin apenas como forma de desestabilizar o argumento do desígnio. ${ }^{3}$ Além disso, argumenta Dennett que, na parte XII dos Diálogos, Filo admite que mesmo que abandonássemos a hipótese de Cleantes ainda assim teríamos de nos contentar com a Mente como princípio originário. Ora, é exatamente esta noção, de acordo ainda com Dennett, que deveria ser abandonada! Mas como podia Hume abandonar esta idéia, afirma Dennett, se ele não dispunha de nenhuma alternativa para o problema em pauta? Enfim, não teria ocorrido a Hume, conquanto sua perplexidade seja de fato um brilhante insight, que o planejamento seria possível sem um planejador. Parece então, seguindo em parte a trilha de Dennett, que é razoável que se coloque a questão de por que não teria ocorrido a Hume uma hipótese como a sugerida ulteriormente por Darwin. Dennett não se preocupa em resolver este problema, e nem é 
seu objetivo fazê-lo no livro mencionado; mas eu gostaria de mencionar sua leitura da parte XII dos Diálogos, pois penso que a citação dessa parte onde Hume, a partir da segunda intervenção de Filo, adota a noção de "mente" como uma alternativa a "Deus", não capta o verdadeiro significado por ele atribuído a "mente". Examinemos essa passagem onde Filo admitira a Mente como princípio originário:

A conclusão legítima desta investigação é que (...) se não nos contentarmos em atribuir à causa primeira e suprema o nome de Deus, ou Divindade, mas se quisermos variar a designação, que nos restaria senão chamá-la Mente ou Pensamento, dado que se supõe com justiça que ela guarda uma considerável semelhança com essas coisas? (HUME, 1992, p. 170)

Ora, nesta parte XII, Filo está exatamente (como o trecho citado por Dennett também comprova) empenhado em mostrar que seu argumento contra o desígnio seria válido para a suposição da causa primeira como "Deus" ou "Mente" ou "Inteligência". Agora, estaria Hume a capitular nesta parte final dos Diálogos? Todo o problema é demonstrar que esta conclusão (seja "Deus" ou "Mente") se segue dos efeitos que observamos, e alterar os termos não auxilia na solução da questão.

Outro defensor da idéia de que Hume não ofereceu alternativa ao argumento do desígnio é Richard Dawkins. Para ele, ${ }^{1}$ Hume teria apenas liquidado o argumento do desígnio, mas teria "subestimado a complexidade e a beleza do desígnio biológico". ${ }^{2}$ O problema com essa hipótese é que ela não parece levar em conta as similaridades entre o contra-argumento de Filo antes apresentado (da parte VIII dos Diálogos), a interpretação do próprio Dawkins do argumento de Darwin e sua "descrição" (hipotética, é claro) do surgimento da estabilidade no universo. Para Dawkins (1989, p. 12), a idéia darwinista de "sobrevivência do mais apto" deveria ser substituída (sem prejuízo para Darwin) pela noção mais ampla de "sobrevivência do estável" (onde o fittest seria um caso especial da sobrevivência do mais estável). E, quando Dawkins "descreve" o surgimento da estabilidade, o faz em termos bastante humeanos (como Filo o fez na parte VIII), da seguinte forma: no meio de todas as moléculas que lutavam pela sobrevivência, uma delas teria conseguido, por acaso, fazer uma réplica de si própria. Com o surgimento desta replicadora, começou a surgir a estabilidade. ${ }^{3}$ Ora, não era exatamente este o núcleo do argumento Filo-Hume, a passagem do caos para a ordem sem a orientação de um planejador? 
Contudo, nem todos os pensadores se "limitam" a conceder a Hume algo mais do que os méritos de uma boa crítica; há aqueles que percebem, na crítica humeana ao argumento do desígnio, um momento construtivo da história da filosofia. Para este trabalho, a orientação geral de perceber em Hume um momento construtivo da história da filosofia ilumina meu objetivo mais modesto de percebê-lo, igualmente, como um filósofo que se preocupou em construir uma alternativa ao argumento do desígnio. Neste caso, é importante revelar algumas fontes decisivas para a minha proposta.

Além do já citado Oppy (que abaixo será novamente considerado), a hipótese de Hume como um precursor de Darwin é defendida também por João Paulo Monteiro. Para Monteiro, Filo insiste na idéia de que uma explicação deve seguir o princípio da eliminação de causas desnecessárias, de modo que não se inflacione metafisicamente a própria explicação. Nesse caso, haveria duas opções: o argumento do desígnio e a disposição interna da natureza, que não permitiria o desajuste (excessivo) entre ela mesma e os seres vivos. Ora, é evidente que a segunda opção é metafisicamente recessiva, e é por isso que deve ser preferida. Ela não corta o mundo em suas juntas (para usar uma expressão tipicamente realista), mas é preferível a suas rivais inflacionárias e adiposas. Talvez esta idéia fosse corroborada pela atitude metodológica adotada por Hume, pois se é possível a explicação através de expedientes pouco onerosos, por que acrescentar entidades que poderiam ser eliminadas sem nenhuma perda epistêmica? Na avaliação de Monteiro, Hume não estaria a considerar o argumento do desígnio como uma boa alternativa, pois a adaptação é uma condição necessária para a sobrevivência dos seres vivos. A verdade é que não há mistério, e a questão que o argumento do desígnio se propõe solucionar não se coloca, pois “(...) significa simplesmente que nenhum ser vivo não adaptado ao seu meio ambiente é capaz de sobreviver, de modo que não tem sentido algum insistir na sua admirável adaptação" (MONTEIRO, 1984, p. 121). Monteiro ainda argumenta, contra as alternativas que alegam o caráter apenas negativo da exposição de Filo no debate, que a única hipótese formulada por Filo que restaria nos Diálogos seria a da adaptação na natureza. Como sabemos, esta adaptação seria conduzida pelo hábito, “(...) um instrumento viável de adaptação ao ambiente que a nossa espécie partilha com as outras espécies animais" (MONTEIRO, 1984, p. 133). Acrescente-se que Monteiro vincula o argumento de Filo ao princípio da indução, de modo que tornaria significativa a adoção da hipótese do hábito. Além disso, insiste em que o princípio da parcimônia ou simplicidade (cuja inspiração deriva do modelo 
de explicação newtoniano) é suficiente para Hume rejeitar o argumento do desígnio, isto é, a natureza se comporta de forma a preservar o equilíbrio das partes, eliminando violentamente as formas de vida caóticas; desta forma, o seu princípio de seleção é tudo o que precisamos para dar conta do fenômeno da adaptação. ${ }^{1}$

Outro filósofo alinhado com esta hipótese é Gaskin (1993). De acordo com ele, mesmo sem dispor de algo como a teoria do big bang, Hume já teria antevisto uma alternativa que ao mesmo tempo mostrava que o argumento do desígnio seria defeituoso. ${ }^{2}$ Gaskin aponta a hipótese de Filo-Hume (da parte VIII), em que a ordem emergiria do caos, como um processo "aparentado" com o da seleção natural. ${ }^{3}$

Subscrevo inteiramente as hipóteses de Oppy, de Monteiro e de Gaskin. Além disso, o que era a hipótese de Filo senão um watershed ${ }^{4}$ na história do argumento do desígnio? E o era, não apenas por demonstrar inconsistências internas ao argumento (como toda parte $\mathrm{X}$ dos Diálogos se dedicava a mostrar); mas, sobretudo, por apresentar (ainda que do ponto de vista meramente teórico) insights que seriam depois "materializados" numa admirável teoria científica, a teoria da evolução pela seleção natural. Esta, como se sabe, tende a preservar formas de vida que eliminem condições desfavoráveis (como a desordem) e preservar formas de vida que agrupem ao máximo condições úteis e favoráveis; e nela, como argumenta Monteiro, não há mistério. Mas, se não há mistério, há ao menos dois problemas com esta linha argumentativa. Em primeiro lugar, para John Mackie, ${ }^{5} \mathrm{o}$ argumento de que não há mistério poderia incorrer numa petição de princípio: as coisas são assim porque, afinal de contas, de outro modo, não seriam como são (e isto tornaria a sobrevivência inviável). O próprio Cleantes argumenta neste sentido (ainda na parte VIII), e a resposta de Filo é decisiva para o que pretendo demonstrar mais abaixo neste artigo, qual seja, que essa é uma questão que não pode ser respondida em termos de sim ou não. Em segundo lugar, a própria noção de "mistério" parece aqui residir num nível diferente daquele em que deveria. Na verdade, há mistério, e muito. Quando Monteiro utiliza a idéia de "disposição interna da natureza", ele está a pensar numa questão genuinamente epistemológica: é preferível crer na disposição interna da natureza, do que no argumento do desígnio. O problema é que, para o problema da explicação, o argumento de Filo-Hume-Darwin parece ser menos simples do que o argumento do desígnio.

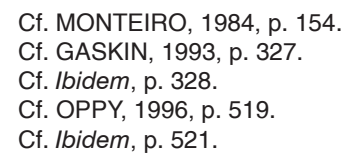


Eu penso que estamos diante de uma ilusão ontológica: a explicação de Hume apela apenas à disposição interna da natureza que é, decididamente, menos inflacionada (ontologicamente) do que o argumento do desígnio. No primeiro caso, temos de aceitar apenas a existência de certos fatos observáveis e algumas hipóteses (o que não vem ao caso agora), enquanto, no segundo, apelamos (para além destes fatos observáveis) à existência de uma entidade para a qual não possuímos acesso epistêmico. Ou seja, a ontologia inclusa no argumento do desígnio é decididamente mais obesa. No entanto, penso que Hume não estava a tratar de ontologia quando da discussão do argumento do desígnio. E, para aqueles que percebem em Hume um precursor do darwinismo (como Monteiro, Oppy e Gaskin), o ponto em questão, creio, reside na explicação, ao invés, por exemplo, de residir na ontologia. Assim, assumir uma alternativa ao argumento do desígnio, na forma proposta por Hume e, além disso, argumentar contra a hipótese de que ele seria apenas um contendor anti-teológico, significa assumir um risco de que sua explicação talvez não seja mais simples do que a proposta no argumento do desígnio, ainda que certamente seja a mais viável para uma epistemologia empirista (o grau de crença parece ser menor) e para a ontologia (postulam-se entidades em menor número).

Deixo aqui em aberto, conquanto tenha todas as simpatias por esta leitura, se Hume capacitou-se a ser um precursor de Darwin. De fato, interessa-me outra questão, que nasce da tréplica de Filo a Cleantes, quando este contraargumenta à idéia pré-darwinista de Hume já referida. Filo, em sua tréplica, não rejeita a réplica de Cleantes; inclusive, festeja o fato de que seu oponente inferiu a imperfeição da hipótese anti-desígnio. Mas, com isso, não se segue que Filo tenha concedido o argumento a Cleantes; antes, está a conceder que sua alternativa não está livre de problemas. Ora, mas então perguntemos a Hume por que deveríamos aceitar seu argumento e rejeitar o argumento do desígnio. Creio que há quatro níveis de análise para o encaminhamento de uma resposta.

Em primeiro lugar, o nível epistemológico. Certamente, há menos crença envolvida na alternativa humeana do que no argumento do desígnio. Contudo, esta solução é insatisfatória, pois se o problema fosse apenas uma questão de crença, uma alternativa ao argumento do desígnio seria o agnosticismo. Mas, uma vez que decidimos encarar Hume não apenas como um desafeto do argumento do desígnio, mas igualmente como um filósofo interessado em fornecer uma alternativa ao problema em pauta, parece, então, que o nível epistemológico não é suficiente para nos convencermos da hipótese humeana. Em segundo lugar, o nível ontológico. Como já mostrei, o argumento do desígnio é, do ponto de vista ontológico, efetivamente perturbador para filósofos empiristas. 
Mas o próprio debate (dos Diálogos) é assentado em algumas regras. Uma delas, estatuída na parte II, aceita ao menos por Filo e por seu proponente Demea - talvez não seja por Cleantes, mas é suficiente, para meu argumento, que seja aceita por Filo - é de que a discussão é referente à natureza de Deus, e não à sua existência. Desse modo, o que está em jogo é a possibilidade da inferência à existência de Deus, antes de um argumento ontológico. ${ }^{1}$ Em terceiro lugar, o nível semântico. Penso que, neste domínio, uma leitura menos restritiva do parágrafo 17 da Investigação sobre o Entendimento Humano, em conjunto com o argumento de Monteiro sobre a conexão entre o hábito (um mecanismo teórico para Hume) e a adaptação, são suficientes para mostrar que Hume não está a reivindicar seu argumento com base numa teoria do significado. De resto, o uso de uma teoria semântica por parte de Hume serviria, neste contexto, apenas para desestabilizar (se de forma coerente ou não, isto não vem ao caso agora) o argumento do desígnio, e não para fornecer um novo argumento. Resta, em quarto lugar, o nível explicativo. Penso que é neste nível que se encontra a força do argumento humeano; além de ser a partir dele, acredito, que o defensor da hipótese de Hume como um pré-darwinista deva se manifestar. Para Hume, as evidências factuais apontam para uma explicação que simplifica, com base na uniformidade ou ordem, a hipótese da adaptação dos meios aos fins. Ora, o ordenamento é um fato, tanto para Hume quanto para o defensor do argumento do desígnio. Mas ele pode ser explicado de forma que não necessitemos apelar a um princípio regulador do ordenamento, entendendo aqui tal princípio como residindo fora daquilo que se quer explicar, no caso, um agente causal não material. Contudo, esta explicação não será mais simples pelo fato de, por exemplo, evitar o regresso ao infinito; ou ainda, por não postular causas desnecessárias. Ademais, isto seria insuficiente para caracterizarmos Hume como um precursor de Darwin. A explicação de Darwin, até onde sei, não é mais simples do que a explicação pela ação do designer que, por meio de um mero fiat, tudo resolveria. A hipótese de Hume-Darwin, ao invés, é bastante problemática em termos de explicação alternativa ao argumento do desígnio. ${ }^{2}$ Contudo, ela explica mais. Ela explica, por exemplo, o

Cf. OPPY, 1996, p. 524.

Creio que esta distinção de níveis é extremamente relevante para que não se confundam extensões teóricas que nem sempre estão alinhadas. Smart, por exemplo, argumenta que a hipótese que levar em conta o postulado de Deus é mais complexa, pois além de toda a complexidade do próprio universo, ainda haveria de se investigar a complexidade de Deus (cf. SMART, 1985, p. 275-276). Ora, ao se tratar de uma hipótese, não necessariamente está se comprometendo com a totalidade dos elementos ontológicos que possam ser incluídos na análise. Assim, uma hipótese anti-deísta não levaria em conta a entidade "Deus". O "problema" do ordenamento poderia ser conduzido sem referência a "Deus", assim como muitas vezes foi conduzido sem referência a "proteínas", por exemplo. A complexidade da hipótese não é apenas uma função da inflação ontológica à qual possa ser submetida; do contrário, ou seja, se o ponto em questão é simplesmente o de aumentar a complexidade das hipóteses, penso que talvez nunca alcançaríamos explicação alguma. 
fato de a espécie humana ser constituída organicamente de uma certa forma, mas, ao fazê-lo, constrói uma longa cadeia argumentativa decididamente mais complicada do que aquela encontrada na afirmação da criação divina. Portanto, há um ganho explicativo, mas com o preço da perda da simplicidade oferecida pelo argumento do desígnio.

É óbvio que as considerações de ordem epistemológica e ontológica estão presentes na avaliação de Hume, pois não consigo compreender os Diálogos como deslocados das teses humeanas acerca dos limites do entendimento humano. Contudo, tenho a impressão de que há uma inegável precedência do problema da explicação; do contrário, por que simplesmente não excluir este problema a partir da adoção de uma semântica mais severa, ancorada numa ontologia beligerante com relação à admissão de inoberváveis? E, como lembra Gaskin (1993, p. 326), Hume também estava a questionar a razão pela qual haveria necessidade de explicar a ordem do universo pressupondo um ordenamento inicial. Naturalmente, se desde o início dos tempos houvesse ordem, não haveria igualmente necessidade de explicação. É exatamente a hipótese (audaciosa, na época de Hume, e mesmo depois, e talvez até hoje em circuitos não acadêmicos) de que seria o caos do início que dramatiza a questão, ou melhor, que a torna um problema genuíno.

\section{Referências Bibliográficas}

DAWKINS, R. The Selfish Gene. 2. ed. Oxford: Oxford University Press, 1989.

DENNETT, D. Darwin's Dangerous Idea: Evolution and the Meanings of Life. New York: Simon \& Schuster, 1996.

GASKIN, J. C. A. Hume on Religion. In: DAVE, Fate Norton (Ed.). The Cambrigde Companion to Hume. Cambridge: Cambridge University Press, 1993.

HUME, D. An Enquiry concerning Human Understanding. In: Great Books of Western World. Chicago: Britannica, 1952.

. Diálogos sobre a Religião Natural. São Paulo: Martins Fontes, 1992.

MONTEIRO, J. P. Hume e a Epistemologia. Vila Maia: Casa da Moeda, 1984.

MOUNCE, H. O. Hume's Naturalism. London: Routledge, 1999.

OPPY, G. Hume and the Argument for Biological Design. Biology and Philosophy, n. 11, 1996.

PENELHUM, T. Hume. London: MacMillan, 1975.

SILVA, M. O problema de uma teoria do significado em Hume. Síntese, Belo Horizonte, v. 31, n. 101, p. 389-404, 2004.

SMART, J. J. C. Laws of Nature and Cosmic Coincidences. The Philosophical Quarterly, v. 35, n. 140, 1985.

STROUD, B. Hume. London: Routledge, 1977. 


\section{Apêndice}

Este artigo foi redigido inicialmente (em 2002) como parte de tese de doutoramento; em seguida foi enviado à revista Kriterion. Entre sua avaliação e sua aceitação pelo menos um artigo foi publicado sobre o tema: "A Crítica de Hume ao Argumento do Desígnio", por José Oscar de Almeida Marques, na revista Doispontos, vol. 1, número 2. Em linhas gerais, o artigo do professor José Oscar indica que o argumento do desígnio não teria sido abalado pelos Diálogos; além disso, e até por conta deste insucesso (o termo é meu) de Hume, o professor José Oscar não aponta Hume como um filósofo que teria antecipado Darwin (levando em consideração inclusive o fato de que Darwin não o menciona como um dos precursores da evolução). Para o professor José Oscar, porque Hume não estipulou os mecanismos da variação, então a passagem do caos para a ordem não estaria explicada no sistema de Filo.

Não quero, neste apêndice, argumentar contra o que foi brilhantemente defendido pelo professor José Oscar (por intermédio do qual, gostaria de registrar, tive meu primeiro contato com os Diálogos - por sua tradução que, inclusive, foi utilizada neste artigo) mesmo porque tenho a impressão de que a questão é indecidível; ou melhor: tanto ele quanto os comentadores citados neste artigo parecem oferecer argumentos que considero bastante plausíveis e interessantes. Porém, todos estes argumentos têm por objetivo determinar se houve ou não a precedência de Hume sobre Darwin; com relação a este aspecto, como já me manifestei neste artigo, penso que a precedência existe (ao menos de um ponto de vista teórico, e com relação a um princípio teórico bastante amplo, tal como foi formulado por Dennett (ou seja: o princípio da ação da matéria sem a intervenção de um planejador). Não obstante há uma outra questão que meu artigo, de forma breve, apenas indicou: a questão da tolerância argumentativa. Quando Filo, na parte VIII dos Diálogos, percebeu que sua alternativa não estava imune a problemas, ele não tratou de defendê-la (e quem de nós sabe onde esta defesa terminaria?), mas se empenhou em mostrar a Cleantes que todos os sistemas - seja o próprio, seja o articulado por meio do argumento do desígnio - estão envolvidos em dificuldades. E, se um argumento como o do desígnio tinha a pretensão de se estabelecer sem levar em conta tais dificuldades (sobretudo dificuldades empíricas), então Hume tem sim o mérito de ter alertado para esta pretensão; porém de minha parte confesso não saber se isto era o caso na época de Hume. 